Sub-categorisation into interval and non-interval types was consistent in 21/35 cases, $\mathrm{k}=.417$ (95\% CI, .305 to .529), $\mathrm{p}<0.0005$.

Altering location of adenomas to adjacent segments did not affect assessment of most plausible explanation in any of the cases.

\begin{tabular}{llll} 
Abstract PTH-005 Table 1 & Most Plausible Explanation \\
\hline Most Plausible Explanation & Assessor 1 & Assessor 2 \\
\hline $\begin{array}{l}\text { Likely incomplete resection of previously identified } \\
\text { lesion }\end{array}$ & 2 & 0 \\
$\begin{array}{l}\text { Detected lesion, not resected } \\
\begin{array}{l}\text { Possible missed lesion, prior examination adequate } \\
\text { Possible missed lesion, prior examination negative but }\end{array}\end{array}$ & 21 & 4 \\
inadequate & 3 & 21 \\
Likely new CRC & 2 & 8 \\
\hline
\end{tabular}

Conclusions The inter-rater agreement for most plausible explanation of PCCRC is almost perfect, indicating that the WEO algorithm is reproducible in a real-world setting. Interrater agreement for categorisation of PCCRC was moderate, most likely reflecting the fact that patient notes were not reviewed in higher detail in this study, making intended interval times not always available to assessors. Altering adenoma location did not affect results, but larger sample sizes are required to assess this further.

\section{PTH-006 COMPLEXITY OF POLYPS IDENTIFIED VIA BOWEL SCREENING PROGRAMME IN NHS GREATER GLASGOW AND CLYDE}

${ }^{1}$ Thomas Berriman*, ${ }^{2}$ Emily Brownson, ${ }^{2}$ Lynn Pace, ${ }^{2} J$ udith Morris, ${ }^{2}$ Jack Westwood Winter. ${ }^{1}$ NHS Education Scotland, Glasgow, UK; ${ }^{2}$ NHS Greater Glasgow and Clyde, Glasgow, UK

\subsection{6/gutjnl-2019-BSGAbstracts.31}

Introduction Colonic polyps are a common finding in the bowel screening colonoscopy program (BCSP). Standard practice is to remove at index colonoscopy if possible. The SMSA polyp scoring system is a method of scoring the difficulty of polypectomy and is not currently recorded in routine practice in our institution. We wished to prospectively audit the spread of SMSA scores in polyps identified in BCSP colonoscopy in NHS Greater Glasgow and Clyde (GGC). Knowledge of the frequency of higher SMSA scores will allow resource planning for the volume of cases which need to be undertaken by an expert endoscopist. We also anticipated the exercise would be formative to our cohort of BCSP colonoscopists when assessing adenoma complexity.

Methods NHS GGC features 8 endoscopy units with BCSP colonoscopy performed at all sites. Between 1st November 2017 and 28th February 2018 we prospectively audited the spread of complexity of adenomas detected on bowel screening colonoscopy. We recorded SMSA polyp characteristics, endoscopic techniques used and the deferral rate and reason.

Results 626 records of polyp assessment were returned. 149 were excluded (outwith date window, invalid CHI, non-BCSP colonoscopy indication). 477 polyps were therefore included in the audit, from a total of 207 BCSP endoscopies. This cohort comprised approximately $30 \%$ of bowel screening colonoscopies undertaken during that time period. 16
Colonoscopists performed BCSP colonoscopy in the studied time-frame: 1 nurse endoscopist, 2 gastroenterologists, 13 colorectal surgeons.

The range of SMSA Scores for polyps was 4-17 (Median 6). $174(36.5 \%)$ were level 1 polyps, 259 (54.3\%) were level 2 polyps, $32(6.7 \%)$ were level 3 polyps and $7(1.5 \%)$ were level 4 polyps.

457 Polyps were removed at index colonoscopy (96\%). Polypectomy deferral rates varied by SMSA level: 42.9\% (3 of 7) for SMSA Level 4 polyps, 18.8\% (6 of 32) for SMSA level 3 polyps, $1.5 \%$ ( 2 of 259 ) for level 2 polyps, and 4\% (7 of 174) for level 1 polyps. The commonest reason for deferring level 1 and 2 polyps was failure to stop the patient's anticoagulant or antiplatelet medication.

Conclusion $8.2 \%$ of polyps detected on bowel screening colonoscopy were SMSA level 3 and 4. The majority of these were removed at index colonoscopy. It is uncertain whether removal at index procedure was uniformly the correct approach in patients with level 3 and 4 polyps and we require to do further research looking at completeness of excision. This audit was undertaken when Guaic based faecal testing was being utilised by the bowel screening programme. Since the change to Faecal Immunochemical Test with a threshold of $80 \mathrm{ug} / \mathrm{g}$ stool we have seen an increase in adenoma detection rates from $40 \%$ to $52 \%$ and therefore the spread of SMSA scores may have changed.

\section{PTH-007 ENDOSCOPIC REMOVAL OF ADENOMAS INVOLVING APPENDIX BASE IS TECHNICALLY FEASIBLE USING FULL THICKNESS RESECTION DEVICE}

${ }^{1}$ Phil Boger*, ${ }^{1}$ Imdadur Rahman, ${ }^{2}$ Fergus Chedgy, ${ }^{2}$ Susi Green, ${ }^{3}$ Perminder Phull, ${ }^{4}$ Siwan Thomas-Gibson, 'Praful Patel. 'University Hospital Southampton Nhs Foundation Trust, Southampton, UK; ${ }^{2}$ Brighton and Sussex University Hospitals NHS Trust, Brighton, UK; ${ }^{3}$ Aberdeen Royal Infirmary, Aberdeen, UK; ${ }^{4}$ St. Marks Hospital, London, UK

\subsection{6/gutjnl-2019-BSGAbstracts.32}

Introduction Endoscopic resection of adenomas involving the appendiceal base is challenging and often technically impossible with resultant necessity for surgery. Endoscopic full thickness resection (eFTR) using the full thickness resection device (FTRD) is a novel technique for removing lesions in the colorectum unresectable by conventional methods. We report use of this technique and outcomes for adenomas involving the appendiceal base.

Methods Data was collected and analysed on patients who underwent eFTR of adenomas involving the appendix base in the UK from April 2015 - January 2019. Main outcome measures were technical success, procedural time, specimen size, R0 resection, endoscopic clearance, and adverse events including appendicitis, and need for surgery.

Results 10 cases were identified across 4 sites where eFTR was attempted for adenoma at the appendix base. Mean patient age was 68 years (range 57-78). 3/10 had previous attempts at EMR and 2/10 had prior appendicectomy.

In 9/10 patients the lesion was reached with the FTRD, with failure of insertion in $1 / 10$ due to sigmoid diverticulosis. The procedure was technically successful in 9/9 patients. Median procedure time was 72 minutes (50-97) and median resection time 6 minutes (4-17). Antibiotics were given in all cases. Median hospital stay was 1 day (1-3).

Median specimen size was $26 \mathrm{~mm}(15-35)$, and full thickness resection was achieved in $7 / 9$ and $\mathrm{R} 0$ resection in $6 / 9$. In 
those where R0 resection was not achieved, $2 / 3$ had residual lesion at follow up; one residual lesion removed by snare, one had clip still in situ and awaiting use of clip cutter to facilitate residual polyp removal. Overall endoscopic clearance rate to date is $89 \%(8 / 9)$.

One patient developed appendicitis at day 6 which required surgery to remove a gangrenous appendix. The patient made an uneventful recovery. Appendicitis rates for this cohort was therefore $14.2 \%(1 / 7)$ when those with prior appendicectomy were excluded. No other complications occurred.

Conclusions Removal of adenomas at the appendix base by eFTR is technically feasible and can avoid the need for surgery. Rates of appendicitis in our cohort are significant and similar to published data ${ }^{1}$, suggesting the need for careful consent and close observation post procedure.

\section{REFERENCE}

1. Schmidt A, et al. Gut 2018; 67: 1280-1289.

\section{PTH-008 ENDOSCOPY REPORTING IN ULCERATIVE COLITIS: IDENTIFYING AREAS OF SUBOPTIMAL PRACTICE TO DEFINE AN INTERVENTION BUNDLE}

Tom Calderbank*, Grace Black, Holly Theaker, Mark Samaan, Oliver Tomkins, Maria Aslam, Simona Di Caro, Farooq Rahman, Shameer Mehta, Sara McCartney, Stuart Bloom, Roser Vega, Edward Seward. Department of Gastroenterology, University College Hospital, London, UK

10.1136/gutjnl-2019-BSGAbstracts.33

\section{Abstract PTH-008 Table 1}

\begin{tabular}{|c|c|c|c|c|}
\hline $\begin{array}{c}\text { BRIDGe endoscopic reporting } \\
\text { criteria }\end{array}$ & $\begin{array}{c}\text { Overall } \\
n=227(\%)\end{array}$ & $\begin{array}{c}\text { Consultant } \\
n=109(\%)\end{array}$ & $\begin{array}{c}\text { Non-Consultant } \\
n=118(\%)\end{array}$ & $p$ \\
\hline $\begin{array}{l}\text { Description of previous } \\
\text { disease extent }\end{array}$ & $6(3)$ & $2(2)$ & $4(3)$ & 0.68 \\
\hline $\begin{array}{l}\text { Specific indication for } \\
\text { procedure described }\end{array}$ & $181(80)$ & $83(76)$ & $98(83)$ & 0.25 \\
\hline $\begin{array}{c}\text { Specific UC therapy at the } \\
\text { time of procedure } \\
\text { documented }\end{array}$ & $22(10)$ & $6(6)$ & $16(14)$ & $0.045^{*}$ \\
\hline $\begin{array}{c}\text { Description of symptoms at } \\
\text { the time of endoscopy }\end{array}$ & $21(9)$ & $8(7)$ & $13(11)$ & 0.37 \\
\hline $\begin{array}{c}\text { Description of maximal extent } \\
\text { of endoscopically visible } \\
\text { disease }\end{array}$ & $196(86)$ & $95(87)$ & $101(86)$ & 0.85 \\
\hline Mayo score & 131 (58) & $64(59)$ & $67(57)$ & 0.79 \\
\hline UCEIS score & $3(1)$ & $0(0)$ & $3(3)$ & 0.25 \\
\hline Segmental biopsy description & $190(84)$ & $85(78)$ & $105(89)$ & $0.031 *$ \\
\hline Overall summary of findings & $178(78)$ & $86(79)$ & $92(78)$ & 0.87 \\
\hline $\begin{array}{l}\text { Recommendations for } \\
\text { treatment documented }\end{array}$ & $68(30)$ & $29(27)$ & $39(33)$ & 0.31 \\
\hline $\begin{array}{c}\text { Follow-up instructions } \\
\text { documented }\end{array}$ & $176(78)$ & $81(74)$ & $95(81)$ & 0.27 \\
\hline $\begin{array}{l}\text { Median overall score out of } \\
11 \text { reporting items }\end{array}$ & 5 & 5 & 5 & 0.07 \\
\hline
\end{tabular}

